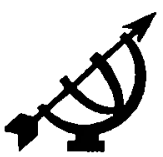

\section{The complexity of science}

\author{
H.P.P. (Hennie) Lötter \\ Department of Philosophy \\ Rand Afrikaans University \\ JOHANNESBURG \\ E-mail: HPPL@lw.rau ac za
}

Abstract

The complexity of science

In this article an alternative philosophy of science based on ideas drawn from the study of complex adaptive systems is presented. As a result of the enormous expansion in scientific disciplines, and the number of scientists and scientific institutions in the twentieth century, I believe science can be characterised as a complex system. I want to interpret the processes of science through which scientists themselves determine what is regarded as good science. This characterisation of science as a complex system can supply an answer to the question why the sciences have been so successful in solving growing numbers of problems and correcting their own mistakes.

I utilise components of complexity theory to explain and interpret science as a complex system. I first explain the concept of complexity in ordinary language. The explanation of science as a complex system starts with a definition of the basic rules guiding the behaviour of science as a complex system. Next, I indicate how various sciences have resulted through the implementation of these rules in the study of a specific aspect of reality. The explanation of the growth of science through evolutionary adaptation and learning forms the core of the article.

\section{Introduction}

Can the new sciences of complexity modify and deepen our everyday understanding of complexity so as to improve our interpretation of science as a complex system? Recent developments in these sciences indicate that we might be on the threshold of startling new developments that could invigorate several sciences in exciting ways. The development of complexity theory with applications across a wide range of disciplines promises to deal with intricate issues and intractable problems (Stein, 1989:xiii), develop theories capable of linking sciences across disciplinary boundaries (Stein, 1989:xv), and modify the domi- 
nant reductionist approach to problem-solving in vogue since the advent of Newtonian science (cf. Cilliers, 1993:4, 5; Casti, 1994:273; Waldrop, 1992:13)

I want to add to the studies in complexity by interpreting science as a complex system in order to provide a better understanding of science as currently practised. Murray Gell-Mann (1994:266) claims that "learning and thinking in general exemplify complex adaptive systems at work" and adds that human creative thinking is perhaps the best expression of those skills. If Gell-Mann's remark is true, one could suspect that science as prime example of human thinking, learning, and creativity should be the most complex system on earth. Whether or not that is true, at least an attempt at explaining science as complex system seems justified.

Can we describe science as complex? We often use the word complex in everyday language. Something is described as complex in everyday language when it consists of a number of parts that vary in kind and importance. Language is a common example of something described as complex. It consists of many kinds of words and sentences, that combine in endless ways according to many rules.

In complex phenomena the relationships between parts differ and are intricate. Human beings are often described as complex, in part because of the intricate and complicated relationships between differing parts, such as brain, blood, muscles, organs, nerves, hormones, emotions, and neurones.

Nevertheless, in complex phenomena these parts combine into a complicated whole with characteristics of its own. A skyscraper requires the complex construction of many different materials in varying relationships, but nevertheless the skyscraper forms a complicated whole with describable characteristics. The combination of parts into a whole can be described in various ways. The parts can be interwoven, connected together, involved in various degrees, intimately mixed, intricately intertwined, entangled, or united. The way different parts are combined in human beings differ from the combinations of parts found in skyscrapers or language.

When phenomena, events, or behaviour are called complex in everyday language, this indicates that people judge such events, phenomena, or behaviour not to be easily analysed or understood. Rather, it is difficult to determine the factors involved and to disentangle them. Not even the best minds in medical science can easily analyse the functions of the parts of the human brain as a complex phenomenon, nor explain their complicated interactions.

Thus, in ordinary language a complex system would be something that defies easy analysis or explanation, consists of many parts that vary in kind and importance, has different relationships between its parts, yet combines the parts 
into a whole that exhibits unique characteristics. According to this definition of the words "complex" and "complexity" in ordinary language, science qualifies as a complex system, as easy explanations of what it is and how it works are not available. The number of parts of science, whether it be specialised fields of study, established theories, or kinds of scientists are overwhelming. The nature of relationships between sciences or among scientists are endless in variety and constantly changing.

In this article I want to present a philosophy of science based on ideas drawn from the study of complex adaptive systems. As a result of the enormous expansion in scientific disciplines, the number of scientists and scientific institutions in the twentieth century, I believe science can be characterised as a complex system. I want to interpret the processes of science through which scientists themselves determine what is regarded as good science. This characterisation of science as complex system can give an answer to the question why the different sciences are so successful in solving growing numbers of problems and correcting their own mistakes.

\section{Science as a complex system}

\subsection{Introduction}

In this section, I want to utilise components of complexity theory to explain science. I will first explain the kind of complexity that seems feasible in an interpretation of science. The explanation of science as a complex system starts with a definition of the basic rules that guide the behaviour of science as a complex system. Next, I will show how various sciences result through the implementation of these rules in the study of a specific aspect of reality. The explanation of the growth of science through evolutionary adaptation and learning will follow next.

\subsection{Explaining complexity}

In the sciences of complexity the concept of complexity gains new meaning as it refers to systems that have the ability to change, evolve, adapt, learn, and reorganise their own structures. Complexity emerges from the collective behaviour of the components of such systems. Many interactions take place between components that can be diverse in form and capability (Holland, 1995:6).

What kind of explanation of the complexity of science is possible? A quantitative explanation of complexity tries to compress the complexity of a system into a measurable or calculable form. This kind of explanation is not possible, as mathematical and computer analyses are not possible for human systems of such high complexity as science (Kline, 1995:96). The farther 


\section{The complexthy of science}

complex systems are from the possibility of directly observing them at work, the more difficult scientific investigation of such systems become (Kline, 1995: 153). Human observers can only observe limited examples of scientists at work; never a representative sample of the overwhelming magnitude of sciences or scientists at work in the world. More access to the work of scientists become possible through reading research reports embodied in articles and books. Whether detailed views enabling quantification of the ever changing scientific disciplines and maps of their continually shifting interconnections and networks are possible seems highly improbable.

A qualitative interpretation of science, in the sense of a synoptic overview providing a broad outline of science as complex system will have to suffice Capturing the complexity of science will entail descriptions or explanations of important processes shaping science. This involves compressing the complexities of science into understandable overviews, based on observations of scientists at work, analyses of research reports, and the interpretations philosophers and historians of science provide

\subsection{Basic rules lead to complex behaviour}

Characteristic of complex systems is that extraordinarily intricate behaviour results from many simultaneous interactions between the components of systems that are governed by a few simple rules (cf. Martin Rees quoted in Brockman, 1995:318; Coveney \& Highfield, 1995:302). Complexities are generated and sculpted by simple rules that enable a myriad possible ways for the components of the system to interact (Waldrop, 1992:86). These rules combine with orderly initial conditions and the operation of chance in a specific space and time resulting in complex structures and behaviour emerging (Gell-Mann, 1994:329). If this is true of science as a complex system, what are the basic rules underlying the complexities of the diverse scientific practices?

I want to provide a first level of analysis of what science is by suggesting a minimal conception of science. This conception is based on the following four rules that are common to both human and natural sciences and are responsible for generating the complexities of modern science. These rules guide the human quest for intelligibility and optimal understanding of the worlds around and within us (Van Huyssteen, 1997:13). These rules are the following:

1. Use specialised problem-solving. Humans are continually involved in problem-solving and science is a specialised way of solving problems. In science problems are solved through research. In scientific research a variety of specialised "instruments" are used to deal with research problems, such as theories, hypotheses, technical equipment (microscopes, measuring instruments, and so on), and methods (interviews, experiments, observation, etc.) 
2. Justify your findings. No findings in science will be accepted if scientists do not provide reasons or evidence in support of them. Findings are as strong as the justifications that fellow scientists can accept.

3. Refer to previous work. In every scientific discipline scientists are part of a history of intellectual developments that have preceded them. To produce acceptable scientific results, scientists must demonstrate that they have noted and are building on the important contributions of their predecessors.

4. Convince your scientific community. No intellectual work can count as a new scientific contribution if it is not accepted by fellow scientists. To produce new scientific results scientists must convince their colleagues that their work was done according to appropriate methods, that all relevant previous work was taken into account, and that their findings fit in with currently firmly established knowledge (cf. Rossouw, 1993:95-97).

These four basic rules are applied by scientists to different fields of study, where different aspects of reality and various kinds of problems are studied. In the process of their application, the basic rules are specified and elaborated. Their specification and elaboration depend on the nature of the objects being studied and the results of the meshing of the rules with the subject matter under investigation. Two examples will illustrate the point.

Human sciences studying literature must devise methods to establish the central themes and meanings of the texts they study. Within these sciences they have several methods that are appropriate for interpreting the meaning of texts. These methods are adapted and complemented depending on the language of the literature, the historical period in which the literary texts originated, and the broad cultural background influencing them. Researchers studying such texts now, must note what their colleagues have already attempted and what has worked and what not. The study of the ancient sacred texts of the Bible might require modified methods from those used to study contemporary English literature, for example. To suggest modified methods requires that a scientist must submit justified proposals to the community of scientists for their judgement whether the proposed method is appropriate and feasible. Specialised problem-solving methods in the literary human sciences are developed to be appropriate to the nature of the objects of study, that is, literature written in a specific language and at a particular time and place in history.

In the case of biology specialised methods of problem-solving are needed that differ substantially from those in the literary human sciences. A biologist studying the migration routes of elephants wants to keep track of their movements. This problem can be solved with the help of satellite navigation systems. If biologists want to study the physiology of elephants, they must know what others have already done, so as not to duplicate their work, to be 
knowledgeable about available information, and to know which are unresolved problems or underresearched areas. Existing knowledge can provide a guide to biologists to get them to the frontiers of knowledge and ignorance. In studying the cardio-vascular system of elephants, biologists might learn useful observational techniques from specialists in human medicine who might have developed sophisticated equipment for observing and studying the human cardio-vascular system. They will have to convince their fellow scientists that these instruments and techniques developed for humans are appropriate for use in the case of elephants, or if they need modifications, the need for such modifications must be argued for with good reasons.

These examples show that the nature of the objects studied, assumed by scientists to be intelligible and open to rational exploration (Van Huyssteen, 1997:219), have a major influence on the development of any science and the way the minimal rules are applied and interpreted

Three further examples drawn from widely differing sciences show in greater detail how the object of study and the nature of the problem under investigation usually dictate the specialised problem-solving methods and techniques for observation and gathering of data. The examples illustrate the ways in which scientists design appropriate tools for investigating particular subject matter and how they gain evidence to justify their findings. The examples are the recent exploration of Mars, the description of the cultural code guiding the meaning of human touch behaviour, and the interpretation of the meaning of an ancient sacred text.

\section{- The exploration of Mars}

The recent exploration of Mars is interplanetary science done by a global team of scientists. The exploration is an example of large-scale scientific research funded by government, done by a large interdisciplinary research team led by the Jet Propulsion Centre at NASA, in collaboration with associates from scientific institutions across the globe. Representatives of several sciences had to co-operate to enable Pathfinder and its rover, called Sojourner, to do its observations on Mars. To get the Pathfinder spacecraft to Mars required knowledge provided by physics and cosmology to enable the craft to land within a $60 \mathrm{~km}$ diameter after a journey of 190 million kilometres. Further scientific knowledge from mathematics and physics was needed to enable the spacecraft to decelerate from the $26200 \mathrm{~km} / \mathrm{h}$ it was travelling when entering the atmosphere of Mars to the $37.6 \mathrm{~km} / \mathrm{h}$ it travelled when hitting the Ares Vallis (Mars Valley). The protection against extreme heat when entering the atmosphere of Mars, as well as the parachute, rockets, and air bags enabling a soft landing are further proofs of the use of sophisticated scientific knowledge and technology required for the mission 
Pathfinder and Sojourner made meteorological, geological, and visual observations on Mars. Meteorological observations were made by instruments measuring windspeed, temperature, and the quality of air. Geological observations were made by an Alpha Proton x-ray spectrometer that can detect the presence of minerals through reading the characteristic emissions projected by specific elements contained in Martian rocks. Magnets mounted on Sojourner attracted magnetic dust which could be analysed by the spectrometer. Visual observations were made of rocks, patterns on the soil, geological formations, and interactions between the Martian surface and its atmosphere. Sets of stereoscopic cameras enabled scientists to estimate the depth, height, and distance of the pictures taken of Mars. All these observations had to be digitally encoded and sent to earth via radio signals. Large dish antennas collected these signais and sent them to JPL in Pasadena, California, via satellite or cable. These coded signals were decoded by computer, projected by means of video technology, and made available on the Internet.

The technology required for making these observations on Mars and the scientific knowledge behind the whole project are staggering. Several subdisciplines of physics are involved, as well as sophisticated mathematical techniques for complicated calculations. Geology and meteorology are deeply involved, as are computer science and different engineering sciences. The scale of the project is so large that dozens of scientists were involved besides the multidisciplinary team at JPL in Pasadena.

\section{- Touch behaviour}

The second example deals with human scientists interested in understanding the cultural meanings that human beings communicate through their touch behaviour. These scientists have similarly combined methods and results from many scientific disciplines. To observe the meanings human beings attach to physically touching other human beings provides a major headache for a scientist studying human communication. Could one observe a sufficient number of people in all possible situations where they touch one another, even if you exclude all sexual behaviour? Suppose you could, would it be possible to deduce the meanings thereof without interviewing both the person who touched and was touched? Jones and Yarbrough (1985) solved this problem by adapting an existing research method in the human sciences, called the method of contextual analysis. Using this method, researchers would make permanent records of the behaviour they want to study through film, video, or auditory recordings. Relevant features of the behaviour are coded and features of the environment and social occasion recorded. These records are used to analyse the behaviour and whether it only occurs when a certain combination of elements is present or not. Jones and Yarbrough modified this method by combining it with participatory observation, a research method developed in anthropology. They trained individuals to make detailed reports about the parts of their body that 
others touched, any comments accompanying the touches, the intended meanings thereof, the time and place it happened, and so on. They provided the participant observers with a "Touch Observation Form" on which they could record all the details of touches

Jones and Yarbrough creatively synthesised two research methods drawn from disciplines other than their own. There are still more traces of other sciences in their development of a theoretical framework within which they understand touch behaviour, conduct their research, and interpret their findings. They constructed their theoretical framework from theories and research findings in nursing science, psychotherapy, psychiatry, psychology, sociology, communication science, occupational therapy, and anthropology. In their analysis of observational data they use several sophisticated statistical techniques.

\section{- The study of ancient sacred texts}

The third example deals with an academic discipline with controversial scientific status. Many people doubt the scientific status of disciplines studying ancient sacred texts such as the Bible. However, scientists in these disciplines are similarly creative in devising methods and techniques and similarly adept at utilising the results of other scientific disciplines for understanding the meaning of even the most obscure ancient sacred text. To decipher the meaning of the notoriously difficult apocalyptic text of Revelation in the New Testament, Jan A. du Rand (1993a, 1993b, 1996a, 1996b) approaches his research problem in ways similar to those of the scientists discussed above. He assumes that Revelation is intelligible, open to rational exploration, and has meaning as a whole

Du Rand's focus is on understanding the meaning of the text of Revelation. As methods he employs textual analysis, literary analysis (aided by insights from musicology), historical analysis, narrative analysis, theological analysis, and the methods of Greek grainmar and syntax. With these methods he searches for patterns and structures in the text of Revelation. He interprets the text as a meaningfully artistic whole through identifying a Leitmotiv, defined as a theme that is "modified on subsequent appearances to represent or symbolise an idea in a dramatic work" (Du Rand, 1993a:304). The idea of a Leitmotiv is complemented by the musicological term, basso ostinato, that he defines as a "short phrase or melody that is repeated over and over in the bass parts" with the function of binding the composition together (Du Rand, 1993a:301)

Du Rand explores the role of concepts like "Zion" and "Spirit" by tracing their meanings in related texts within Jewish religious traditions and through determining their links and contrasts with other parts of Revelation, as well as their function and meaning within the broader theological narrative of Revelation itself. As a result he presents a multitude of textual references to his scientific 
H.P.P. (Hennie) Lötter

community as evidence for his interpretation of the concepts "Zion" and "Spirit".

Almost inseparable from these textual analyses are his attempts to place the text within various contexts, leading him to discover intertextual links with texts from the Old Testament, ancient Jewish and Greek literature, and other New Testament texts. He further contextualises Revelation within the history and religious traditions of Israel, the ancient Near East, and early Christianity. His interpretation of the meaning of Revelation rests on the way he activates a multitude of textual evidence to become an intertextual event.

These examples show the development of specialised problem-solving methods and techniques drawn from a variety of sciences that produce evidence acceptable to fellow scientists. The examples also demonstrate the extraordinary ability of scientists to devise new sensors for detecting and observing phenomena and events in the world in order to gather information for adequately modelling the world.

\subsection{Complex systems gather information about their world}

One of the major capabilities of complex systems is their ability to gather information about the environment and store it for future use (Cilliers, 1993:18). The process of gathering new information is crucial for most sciences. Through new techniques of observation, new findings, and new explanatory theories scientists collect, analyse, and interpret data about the worlds around us and within ourselves. The sciences deal in diverse ways with different kinds of subject matter in the process of the gathering of data. Scientists devise creative methods and ingenious techniques for increasing precision in gathering information about the world. Increased precision results from specialised problem-solving applied to the demands of the specific objects of study. New scientific developments can increase the precision of information, as the following discussion will illustrate.

Aristotle, one of the greatest scientists ever (cf. Dunbar, 1995:37-40), argued in his Nichomachean Ethics that his discussion of ethics will be adequate if it has as much "clearness as the subject-matter admits of, for precision is not to be sought for alike in all discussions" (Aristotle, 1925:2, 3). His argument is that the ethical actions he is investigating exhibit much variety and fluctuation and therefore he must be content to speak of his subject with premises that indicate the truth "roughly and in outline". An educated person would expect no more, as such a person knows to look for precision in each class of things "just so far as the nature of the subject admits". Conversely, Aristotle says, an educated person would not foolishly accept probable reasoning from a mathematician, nor demand demonstrative proofs from a rhetorician (Aristotle, 1925:3) 
Aristotle's argument that the degree of precision possible in a science depends on the nature of the subject matter studied is still valid today. His point can be illustrated by remarks made by an economist, Brian Arthur, trying to explain the economy as a complex adaptive system (cf. Waldrop, 1992:141, 151, 255). Arthur argues that the economy is like the biosphere that is always evolving, changing, and exploring new territory (Waldrop, 1992:255). The difficulty of the science of economics is that the objects of study are imperfectly smart agents who are exploring their way "into an essentially infinite space of possibilities" (Waldrop, 1992:151). Arthur's comparison of the complexities that economics have to deal with in comparison to those of physics are worth quoting in full:

We call our particles 'agents' - banks, firms, consumers, governments ... Our particles in economics are smart, whereas yours in physics are dumb. In physics an elementary particle has no past, no experience, no goals, no hopes or fears about the future. It just is. That's why physicists can talk so freely about 'universal laws': their particles respond to forces blindly, with absolute obedience. But in economics, ... our particles have to think ahead, and try to figure out how other particles might react if they were to undertake certain actions. Our particles have to react on the basis of expectations and strategies ... that's what makes economics truly difficult (Waldrop, 1992:141).

From Arthur's description of the objects of study in economics, it is clear that similar precision as in physics would be virtually impossible, thus excluding also similarly strong causal explanations and accurate predictions of the behaviour studied. This does not imply that scientific advances - new techniques for observation, new findings, new explanatory theories - cannot transform the degree of precision possible in a field of study. An example of the study of human thought processes will illustrate the point.

The study of human thought processes was long ignored in the sciences. These processes were studied for many centuries through introspective methods in philosophy, through analyses of the products of human thinking embodied in texts in literature or logic, through observation of the effects of coincidental cases of brain injury in medical science, or through information gained through dialogue in psychology. However, recent developments in scientific technologies have enabled scientists to observe brain functions through various techniques scanning the brain and to model brain processes through the use of computers and artificial neural nets. These techniques have enabled medical scientists to reach new levels of precision in determining human thought processes underlying various kinds of human activities, such as learning, memory, and speech (Coveny \& Highfield, 1995:11).

\subsection{Complex systems model their worlds}

Complex adaptive systems build models containing assumptions about the world out there that aid them in understanding and anticipating events that influence 
their behaviour (Waldrop, 1992:146, 177). They have to be able to understand and use the information they get from the world through their sensors. Science as complex system continually and actively search for and gather new experience that are packaged as information. Experience must be able to enter the system through sensors. Sensors can be the human senses or methods, techniques, and instruments extending the senses. Characteristic of science is the multiplicity of sensors strengthening, amplifying, and complementing human senses.

Complex adaptive systems must identify those regularities and patterns in information coming from their environments that are relevant to their purposes (cf. Holland, 1995:31-32). These regularities are condensed into models that enable action and behaviour in the world (cf. Gell-Mann, 1994:17). Models of relevant aspects of their environment must be modifiable so that they can be improved upon receiving new information. Models are continually tried out to determine whether the complex adaptive system can act successfully on their prescriptions and predictions (cf. Holland, 1995:33-34). The results of the action and behaviour must be monitored and fed back to modify the models, if necessary. In the light of experience, the models must be modified (Waldrop, 1992:179)

The results of modelling in the sciences through the observation and interpretation of problems under investigation can be extremely diverse in content and style (cf. Ziman, 1994:179). Despite this diversity contributions to scientific knowledge usually have a publicly shared, quasi-objective, and schematic form similar to those of maps (Ziman, 1995:72). These maps are attempts at modelling the world that are revised or rejected through critical examination and testing. Amongst the diversity of maps provided by scientists are experimental measurements, logical analyses, observational data, theoretical calculations, mathematical models, new theories or hypotheses, instrumental techniques, textual analyses, critical surveys, and pictorial communications of pattern recognitions, such as diagrams, photographs, maps, and graphs (Ziman, 1995:71; 1994:179).

Gathering new experience, recognising pattems, modelling regularities, and modifying models after critical testing lies at the heart of the sciences.

\subsection{Complex systems recombine, rearrange, and revise themselves}

Complex systems continually recombine and rearrange their building blocks and revise their structure and organisation (cf. Waldrop, 1992:145, 146). Complex systems do this as a result of gaining new experience. Rearrangement of components, revision of structure, and recombination of building blocks are the fundamental mechanisms of adaptation, evolution, and learning, which become 
necessary as a result of experience (Waldrop, 1992:146). In the sciences rearrangement, recombination, and revision are common occurrences, despite the attitude of many scientists humorously expressed in the "First Commandment of Academia: Thou shalt not transgress thy disciplinary boundary" (Kline, 1995:5).

This section does not focus on changes in science that result from developments within the boundaries of a specific science, but rather on the way that developments outside the boundaries of a scientific discipline can be used to modify scientific practice within those boundaries. Thus, the focus is not on the effect of new results and theories developed by a researcher of a particular science, but rather on the common phenomenon of rearrangements and recombinations that follow from appropriating new methods, techniques, theories, and results developed elsewhere, by other sciences. The ongoing integration and grafting of elements from other disciplines into one's own are driven by the hope of discovering things in other disciplines that can extend the limits of one's own discipline (Van Huyssteen, 1997:17, 32)

For many decades sciences have been influenced by intellectual developments occurring in other sciences. Obvious examples are the role of mathematical and statistical techniques used for analysis in an ever-growing variety of sciences. But are such influences restricted to borrowing and using these instruments and tools? Are other influences from one scientific discipline to another, such as the transfer of methods, theories, and results, excluded? Definitely not. The three examples of diverse scientific investigations in a previous section demonstrate how various sciences continually rearrange and recombine themselves through selective borrowing and integration of aspects of other disciplines. These recombinations and rearrangements point to the interdisciplinary nature of most sciences.

I want to argue that scientific investigation in one scientific discipline leads scientists to discover overlaps between their field of study and other fields of study. Selective borrowing occurs - without regard for academic frontiers (cf. Ziman, 1995:95) - of methods of investigation, techniques for observation and analysis, tools for computing, results for background knowledge, and theories for explanation and prediction. The result is that several sciences share various aspects of their methods, techniques, and results with one another. For this reason many sciences have lots in common. For example, mathematics, statistics, and computer technology function as instruments for analysis in many sciences. Which aspects, the extent, and depth to which scientists use the tools provided by mathematics, statistics, and computer science vary considerably in widely differing sciences like botany, psychology, and economics. Similarly, theories and results are often shared in many sciences. For example, nuclear physics play an important role in different scientific disciplines, just as theories of interpretation are shared by a variety of human sciences. 
Some sciences are reconstructed through new discoveries, theoretical insights, or new linkages between previously distant disciplines (Ziman, 1994:20, 22). Though scientific disciplines evolve to become more specialised and frequently differentiate and split apart as result, they just as often recombine to form intricate and overlapping connections with one another. Connections are made at theoretical and instrumental levels, boundaries between theories and disciplines are revised, and intellectual mergers between theories and disciplines take place (Ziman, 1995:84). Ziman describes the complexities of these processes as beyond ordinary human understanding (Ziman, 1994:71). Linking previously unrelated information is a typical creative scientific contribution. These recombinations of sciences as a redrawing of the cognitive maps of disciplines is a central theme in the developmental history of the sciences (Ziman, 1994:63).

The sharing and borrowing of methods, techniques, results, and theories suggest that there are more similarities between individual scientific disciplines than thus far suggested. An intermediate conception of science can account for these overlaps and similarities. Such a conception aims to give a description of the nature of science at the level of clusters of individual sciences that are temporarily grouped together through shared interests. The meshing of a few simple rules with the specific subject matter investigated by a scientific discipline does not create sciences that necessarily develop in totally different directions. Shared interests between scientific disciplines abound, as several sciences are closely related. Close relations result from studying similar objects or phenomena or using similar methods, techniques, results, and theories. The similarities and overlaps between sciences are not permanent or fixed, as new relationships and overlaps are constantly forged based on new developments in diverse sciences. Nevertheless, individual sciences cluster together on the basis of shared interests in subject matter, methods, techniques, theories, and results.

Different clusters of sciences might have little more in common with one another than the few basic rules specified above. Sometimes the detailed interpretation of what the few basic rules require with respect to the subject matter under investigation can lead to further distance between sciences, creating a feeling of fragmented discourses that are virtually incomprehensible for people not conversant with its esoteric language (cf. Lyotard, 1979). This often observed inability of communication between scientists from different fields of study can be explained through a maximal conception of science. This conception deals with science on a third level beyond the minimal conception based on basic shared rules and the intermediate conception dealing with overlapping sciences grouped into clusters. This third level of analysis requires an explanation of the ability of complex adaptive systems to self-organise. 


\subsection{Science as a complex system self-organises}

As the number of scientists involved in a particular field of study grows, the scientific discipline starts to become complex. This happens through the ability of complex adaptive systems to self-organise.

Complex adaptive systems have the ability to change and develop their structures with the aim to better adapt to, cope with, or manipulate their environment. They thus continually transform their structures and organisation as a result of rich interactions between components of the system, as well as between the system and its environment. Interaction with the environment is complex, as many parts of the environment are also evolving. One could thus refer to co-evolution, as individuals try to adapt to their evolving environment (cf. Holland, 1995: 10; Waldrop, 1992:259).

Self-organisation does not result from a central controller, as complex systems usually have no central controller with complete control over them. The dynamics of these systems allow a great deal of autonomy, although there might be some tendencies toward central control. The absence of rigid central control results in systems with robust, adaptive, flexible, and innovative organisation (Brockman, 1995:349; Casti, 1994:272)

Self-organisation clearly plays a major role in science. Science is institutionally embodied in universities, research institutes, and industries. At universities the sciences often organise themselves into faculties such as Medicine, Economics, Law, and so on, which cluster together related sciences organised into departments. Some sciences, like particle physics, have become collectivised because research facilities have become extremely sophisticated and expensive. For these reasons they have to be funded by governments and shared by scientists from many different countries, like CERN in Europe (cf. Ziman, 1994 and 1995:364). Not only are these facilities shared, but some experiments involve teams of a hundred scientists and more. Many scientific projects require the input of scientists with various specialised skills drawn from different sciences (Ziman, 1994:60). Similar patterns of collectivisation in other sciences are marked by a large increase in the number of multiply co-authored articles in the last few decades (Ziman, 1995:289).

Through regional and national organisations scientists group together for promoting their disciplinary interests, especially through conferences and the publication of journals Within organisations specialised interest groups arise who share information and exchange ideas. Even smaller formal or informal research groups are formed that collaborate on projects on various levels. Through publications, i.e., journals and books, important forms of self-organisation take place through the selection of editors, editorial boards, and referees. 
Funding agencies also appoint referees for advice on suitable candidates or proposals for research funding.

Self-organisation in science results from the absence of central control. Control over what is accepted as science, is widely dispersed throughout the scientific community (cf. Waldrop, 1992:145). Referees, editorial boards, and editors of thousands of journals and publishers share decisions about what is good science and ought to be published. Committees of countless scientific institutions, composed of experts, determine appointments, promotions, funding, and prizes. Individual scientists involved in research make decisions, gather information, and develop arguments for judging existing research and presenting new findings. Individual scientists often have informal networks of contacts with fellow scientists that are kept up through mail, telephone, guest lectures, and conferences.

The richness of the multiple interactions between scientists demonstrates why self-organisation is possible within the sciences through widely dispersed decision-making powers. As a result the nature, contents, and processes of science are continually adapted to fit better with the environment - whether environment here means the objects of study, fellow scientists, or the current state of the art research findings, methods, and techniques setting the agenda for future research.

The result of the comprehensive ability of the sciences to self-organise through widely dispersed control over what qualifies as good science underlies the third conception of science. The maximalist conception of science analyses science at a third level, viz. that of the community of scientists in a particular field of study. This community of scientists determines the nature, standards, accepted findings, and workable theories of their discipline on a continual basis. As community they decide what kind of research is do-able, what the current state of the art is, and what is well-established in the discipline (Ziman, 1995:273).

The critical scrutiny of experts in a discipline temporarily resolves disagreements - a characteristic feature of science - only to be disrupted again (Van Huyssteen, 1997:250). This never-ending redefinition of what science is by leaders in their fields of study is all we have. These judgements come from within a discipline where scientists know well enough how to distinguish ways of proceeding, whether they are justified or not, fruitful or fruitless, reasoned or not. Putnam's advice is that scientists should not abandon these knowledgeable judgements that they as doers, practitioners, and agents of a specific scientific discipline make (Putnam, 1990) in favour of judgements from outside their discipline imposing standards of science on them.

Competent judgements within a scientific discipline are possible because scientists can learn from history and experience. Through comparison of new 
theories, methods, and findings with what has gone before they can judge the significance of new proposals and decide whether they are better estimates of how the world really is (Van Huyssteen, 1997:253). The acceptance of new contributions results in the reinterpretation of existing information to determine its correspondence and coherence with what has been judged to be the new standard-bearers of significance. As a result selective forgetting takes place, as lost significance implies the death of scientific work, and death means being forgotten.

Different maximalist versions of individual sciences are in interaction with one another and are commonly aggregated under the collective name of science. Clustering together implies the typical behaviour of complex adaptive systems. When similar complex systems are in interaction, they have a tendency to generate other more sophisticated complex systems on a higher level of organisation. Such a complex system of complex systems evolves through the efforts of the complex agents to survive or improve their positions. Such a collective of complex systems are beneficial to the individual complex systems.

Unitary conceptions of science claim to give a reconstructed model of how science, in the sense of a complex system of complex systems, works and ought to work. Thus, what they are doing is to interpret one specific science, usually physics, and generalise those findings to science as the aggregation of complex systems. This generalisation is without grounds. Science as complex system of complex systems is not a single unified and monolithic enterprise, but resembles a "rather ramshackle structure with little coherence among its various parts" (Kuhn, 1970:49). The various sciences cohere on a minimal conception of science, based on a few basic rules, and some sciences cluster together on the basis of shared interests. However, a model developed by philosophers of science - based on the example of one science only - that ought to be normative for all other sciences seems out of the question.

\subsection{Science at the edge between order and chaos}

The processes through which scientists judge the results of new and existing scientific research can be elucidated by another aspect of complex adaptive systems, viz., the fact that they are poised between the edge of chaos and order. The interplays between order and disorder, stability and fluidity, chaos and regularity, and predictability and unpredictability that complex adaptive systems exhibit are regarded as one of their most striking features (cf. Stein, 1989:xiv).

Commonly called the edge of chaos, this expression refers to that part of a complex adaptive system where its components never quite lock into place, yet never quite dissolve into turbulence either. The edge of chaos is described in different ways. Some regard it as the constantly shifting battle zone between stagnation and anarchy (Waldrop, 1992:12), while others interpret it as the 
tension between regulation through feedbacks and creative response to new conditions. The edge of chaos is described as the zone where complex systems can be spontaneous and adaptive, or where new ideas can nibble away at the status quo (cf. Waldrop, 1992:12).

The edge between order and chaos in science lies at the frontiers of new research where research traditions manifest their dynamism in a never-ending dialectic of continuity and change (Van Huyssteen, 1997:33). In most scientific disciplines opinions simultaneously converge and differ on what are established theories, results, methods, and techniques (cf. Rouse, 1990). Scientists have sufficiently overlapping convictions about which important developments have shaped their discipline thus far to enable communication about the significance of new contributions. The shared overlapping convictions enable scientists to discuss differences and to make creative contributions. Yet the overlapping convictions are in continual tension with new contributions that threaten the coherence of the shared convictions of scientists about what scientific results, methods, theories, and techniques are significant and dominate their field.

The edge between order and chaos in science has the stability of some shared convictions about significant work to enable scientists to judge the value of new contributions that threaten to undermine the temporarily established shared convictions of significance. But significance in science means exactly that - to change, modify, or add to the preceding history of significant contributions. Rouse (1990) thinks that scientists live within various ongoing stories, all aiming to push the storyline in diverging directions. The coherence of the narrative documenting significant contributions to the development of the discipline is under continuous pressure to unravel due to new contributions challenging the current state of the art. However, a reasonably coherent narrative is needed that encourages and yet controls controversy (cf. Ziman, 1995:82). By keeping criticism and imagination in continuous tension, differences within a discipline can be kept intelligible and a space exists within which creative work can be done (Rouse, 1990).

Through significant contributions modifying the existing cognitive landscape of a discipline (cf. Ziman, 1995:275), scientists redefine what the field is about and provide new opportunities for research. Solutions to important problems in a scientific discipline necessitate that every scientist must reconsider the contents, methods, and aims of their research programs (Ziman, 1995:279). Scientists read new contributions - published in books or journals - with the aim of discovering new advances at the frontiers of their discipline. Such advances include results they must take account of, research opportunities that they could usefully follow up, or methods and techniques that they might employ (Rouse, 1990).

The contents of a scientific discipline currently accepted as significant and thus dominating research activities in the discipline are constantly exposed to 
problems, pressures, and challenges (cf. Popper, 1981). Theories are examined for their internal coherence, their coherence with established theories and results, and for their fit with available evidence. New findings are under pressure to withstand critical examination of the methods used for data-gathering and whether these methods were consistently and impartially applied. Further pressure comes from investigations determining whether the techniques of analysis were appropriately applied and skilfully handled.

One result of stringent critical examination and rigorous testing of existing scientific contributions is the presentation of imaginative, new scientific theories, results, methods, and techniques. These new proposals aim to correct problems, deal with challenges, and alleviate pressures on existing accepted scientific results. In the process, new contributions proliferate and tend to create a chaotic field of new ideas to be sorted out. Again this leads to creative tension between already accepted scientific results and the newly proposed contributions whose significance are constantly being determined through academic debates, critical scrutiny, and rigorous testing. When significant contributions become accepted part of the body of established knowledge, no state of equilibrium follows. The result rather changes the environment in which scientific research is conducted. The changed environment results in new pressures, problems, and challenges that must be dealt with through similar processes as described above.

The nature of the edge of chaos in science as complex system draws attention to another characteristic of complex systems, viz. components of complex systems co-evolve with their environments. In this case, the components of science can refer to the theories, results, methods, techniques, and the conceptions scientists have of their disciplines, albeit often tacitly. Complex systems are characterised by multiple independent agents that interact with one another in many ways. Each agent are constantly reacting and adapting to what the other agents are doing (cf. Waldrop, 1992:145). For this reason the environment of an agent is not fixed, but constantly evolving. Individual agents must change and improve themselves relative to the evolving changes implemented by other agents.

Successful changes thus depend upon what other agents are around, the success of those agents' adaptation, learning, and evolution, the niche an agent fills, the agent's ability to adapt and leam, and sometimes even the past history of an agent. Fitness, in the sense of either successful adaptation to the environment, or appropriate learning from experience, arises "from the dance of co-evolution" (Waldrop, 1992:259). Science is such a system of co-evolving components. Ziman (1994:78) calls the scientific enterprise a system with closely linked components that are continually evolving. The components - scientists, theories, methods, results, or even disciplines - grow and change in relation to one another. 
The "complexity scientists" use the concept of the edge of chaos in conjunction with the idea of self-organised criticality that states complex systems can tune themselves toward optimum sensitivity to external inputs. In such a state of sensitivity even minor events can start a chain reaction that affects large numbers of elements in the system (cf. Waldrop, 1992:304-305). Such a chain reaction can lead to breakdowns of all sizes ripping through the system and rearranging it. Complex systems in a state of self-organised criticality can be identified if they show waves of changes and upheaval on all scales (Waldrop, 1992:308).

The idea of a state of self-organised criticality in science functions at the level of comprehensive theories. Thomas Kuhn's (1970) concept of scientific revolutions illustrates self-organised criticality at work in major theoretical changes that occur in some sciences. Normal science - in Kuhnian terms - and anomalies prepare the ground for a state of criticality. The research agenda for normal science are defined by comprehensive theoretical frameworks called paradigms Normal science consists of "puzzle solving," as intricate instrumental, conceptual, mathematical, and empirical problems left unresolved by a new paradigm must be solved. The challenge of fitting all the right pieces of the puzzle functions as an important driving force in scientific research.

Growing specialisation through normal science makes a paradigm more precise, accurate, and complicated. Besides strengthening the existing paradigm, growth through normal science also leads to the gradual disintegration of a paradigm According to Kuhn, "the more precise and far-reaching that paradigm is, the more sensitive an indicator it provides of anomaly and hence of an occasion for paradigm change" (Kuhn, 1970:65)

Anomalies disturb normal science and threaten paradigms. Anomalies are new, unknown phenomena that defy easy explanation in terms of the existing paradigm. Normal scientists first try to explain anomalies. If explanations fail, scientists modify the existing paradigm. They try to resist anomalies that can overturn the existing paradigm as far as possible. A paradigm whose explanatory power has diminished as a result of accumulating anomalies leads a scientific discipline into a state of self-organised criticality.

A scientific revolution occurs when a new paradigm replaces the existing one This revolution happens when the new paradigm explains both known facts and anomalies. To reject the existing paradigm is simultaneously a decision to accept the new. The old and the new paradigms cannot coexist, the older one must make way for the new. Paradigms specify the standards for normal science; therefore a scientific revolution changes the way science is practised. Scientific revolutions destroy the weak parts of existing paradigms and incorporate their explanatory successes. 
The relatively minor event of the acceptance of a new comprehensive theory or paradigm starts a chain reaction that affects large numbers of scientists, often in more than one discipline. Breakdowns of all sizes can rip through scientific disciplines and subdisciplines and rearrange priorities among accepted results, dominant theories, and trusted methods or techniques. Kuhn is clear that revolutions of different sizes could occur and that the effects of some revolutions vary on members of different disciplines as a result of the phenomenon that a paradigm can be important for many scientific disciplines, though "it is not the same paradigm for all" (Kuhn, 1970:50).

The influence of an important scientific result can work its way across the conventional boundaries of various disciplines and fields like an epidemic, where "new foci of infection appear unexpectedly at points that are far away from previously affected regions" (Ziman, 1995:94). Galison lists some of the metaphors that have recently been employed for depicting these modifications of current scientific practice. Instead of gradual accumulation, philosophers of science are now referring to epistemic ruptures or fissures, Gestalt shifts, sociological disruptions between generations, or ontological rifts tearing like geological faults between theories (Galison, 1988:204).

\section{Conclusion}

In this article I have presented a view of science based on an appropriation of the theoretical framework of the sciences of complexity. I argued for three conceptions of science, i.e., a minimal conception of science shared by all sciences, an intermediate conception of science where sciences cluster together on the basis of their shared interests and similarities, and a maximalist conception of science determined for each individual science by the community of scientists in that specific discipline.

This project rests on an attempt to describe and interpret the workings of science as a complex system. This approach to philosophy of science fits in with several other contemporary projects that focus on the processes through which scientists themselves determine their scientific disciplines. The project is not an attempt to reconstruct the nature of the products that science delivers and to present prescriptions about how science ought to function

The project is part of a style of philosophising about science that focuses on processes that philosophers detect as common to certain classes of human practices and therefore propose that these processes are common to science as well. Such proposals need feedback and dialogue from practising scientists to determine whether they indeed fit scientific activity. Interdisciplinary dialogue between scientists and philosophers can create shared meaning about the nature, working, and progress of science. 
Three examples of similar projects will suffice. Joseph Rouse (1990) uses the idea of the scripting of the unfolding of a plot in a narrative as metaphor for the struggle among scientists to get priority for their work. Peter Kosso (1992 \& 1996) takes the idea of the hermeneutic circle drawn from the translation of foreign languages and suggests that a similar hermeneutic circle is applicable to all sciences through the reciprocal interaction between theory and evidence. Robert Dunbar (1995) depicts science as specialised, refined methods of problem-solving that build on universally human (and animal) abilities of problem-solving through trial and error.

If this style of philosophising about science finds acceptance, philosophers of science will not be able to legislate about science anymore, but will retain a modest role as interpreters of science. This role can only be fulfilled through interdisciplinary dialogue with practising scientists who have the tacit knowledge and relevant examples of what good science consists of. If practising scientists do not recognise their disciplinary activities in proposed philosophies of science, something has gone awry in philosophy of science (Kline, 1995:253) To avoid that, the philosopher of science will have to rely on studies of scientific literature, interviews, and dialogues with leading scientists, and new ideas from various sciences concerning theories and results that might be applicable to the practices of science. These requirements seem the minimum for dealing with the unique subject matter that philosophy of science itself investigates.

\section{Bibliography}

ARISTOTLE 1925. The Nichomachean ethics. Translated with an introduction by David Ross. Revised by Ackrill, J L. \& Urmson, J O Oxford : Oxford University Press

BROCKMAN, JOHN 1995. The third culture: Beyond the scientific revolution. New York Simon \& Schuster.

CASTI, JOHN L. 1994. Complexification: Explaining a paradoxical world through the science of surprise London: Abacus

CILLIERS, FRIEDRICH PAUL 1993 Modelling complexity. Stellenbosch : University of Stellenbosch. (Doctoral Dissertation.)

COVENEY, PETER \& HIGHFIELD, ROGER. 1995. Frontiers of complexity: The search for order in a chaotic world. London : Faber \& Faber

DU RAND, JAN A. 1993a. A 'basso ostinato' in the structuring of the Apocalypse of John? Neotestamentica, 27(2) 299-311

DU RAND, JAN A 1993b. 'Now the salvation of our God has come.' A narrative perspective on the hymns in Revelation 12-15. Neotestamentica, 27(2):299-311

DU RAND, JAN A 1996a. Die eskatalogiese betekenis van Sion as agtergrond tot die teologie van die boek Openbaring Ongepubliseerde voordrag.

DU RAND, JAN A. 1996b The functional role and theological meaning of the Spirit in the book of Revelation Unpublished lecture.

DUNB AR, ROBIN. 1995. The trouble with science London : Faber and Faber

GALISON, PETER. 1988 History, philosophy and the central metaphor Science in Context, 2(1): 197-212

GELL-MANN, MURRAY 1994 The quark and the jaguar: Adventures in the simple and the complex. London : Abacus 
HOLLAND, JOHN 1995. Hidden order: How adaptation builds complexity. Reading, Massachusetts : Helix Books.

JONES, STANLEY E \& YARBROUGH, A ELAINE 1985 A naturalistic study of the meanings of touch Communication Monographs, 52:19-56.

KLINE, STEPHEN JAY 1995. Conceptual foundations for multidisciplinary thinking Stanford : Stanford University Press

KOSSO, PETER 1992. Reading the book of nature: An introduction to the philosophy of science Cambridge : Cambridge University Press.

KOSSO, PETER 1996 Scientific method and hermeneutics. Southern Journal of Philosophy, $34(2): 169-182$

KUHN, THOMAS 1970 The structure of scientific revolutions (Second Edition, Enlarged) Chicago: The University of Chicago Press.

LYOTARD, JEAN-FRANCOIS 1979 The postmodern condition: A report on knowledge Manchester : Manchester University Press

POPPER, KARL 1981. The rationality of scientific revolutions. (In Hacking, Ian, ed. Scientific revolutions. Oxford Oxford University Press p 80-106)

PUTNAM, HILARY 1990. The idea of science Midwest Studies in Philosophy, 15:57-64.

ROSSOUW, H W 1993. Universiteit, wetenskap en kultuur Kaapstad : Tafelberg Uitgewers

ROUSE, JOSEPH 1990 The narrative reconstruction of science Inquiry, 33(2):179-196

STEIN, DANIEL L, ed. 1989 Lectures in the sciences of complexity Redwood City, Calif. Addison Wesley Publishing Company

VAN HUYSSTEEN, J WENTZEL. 1997 Essays in postfoundationalist theology Grand Rapids, Michigan : Eerdmans.

WALDROP, M MITCHELL 1992 Complexity: The emerging science at the edge of the border between order and chaos London : Penguin Books

ZIMAN, JOHN 1994 Prometheus bound: Science in a dynamic steady state Cambridge Cambridge University Press

ZIMAN, JOHN 1995 Of one mind: The collectivization of science. Woodbury, NY American Institute of Physics Press 